ISSN:

Print - $2277-078 \mathrm{X}$

Online - $2315-747 \mathrm{X}$

(c) FUNAAB 2018

\title{
CONSTRUCTION OF EROTIC NUANCES ON WHATSAPP AND BBM BY NIGERIAN STUDENTS
}

\author{
*0.0. AKINOLA AND A. A. OGUNSANYA \\ D epartment of Mass Communication, O labisi O nabanjo University, Ago-Iwoye, Nigeria \\ *Comesponding Author: akinola.lanre@ oouagoiwoye.edu.ng.
}

\begin{abstract}
WhatsApp and BBM are popular instant messengers among Nigerian youths, particularly those of tertiary education age. Both applications are used by different shades of people across both genders as means to achieve different end. This study investigates how both apps are used in the construction of erotic conversations. The study is exploratory in nature and is intended to sketch initial understanding from different pictures painted by individual participants. Consequently, semi-structured interview of the qualitative method was used to extract responses from 20 participants, 10 each from both genders. All participants were drawn randomly from National Diploma (NDI) students of Mass Communication Department of Lagos State Polytechnic, Isolo Campus, Nigeria and year three and four students of Mass Communication Department of Olabisi Onabanjo University Ago-Iwoye, Nigeria. Findings revealed that for technical, operational and financial reasons, participants prefer WhatsApp to BBM. Majority of their erotic experiences occur on WhatsApp, involving, largely, chat buddies they have physical familiarity with. Also, most of the participants received more of nude, sexually explicit pictures of a chat buddy at some point in their erotic chat experiences in addition to pornographic films and sexually charged voice notes.
\end{abstract}

Keywords: Mobile instant messaging, WhatsApp, BBM, Chat buddies, Erotic.

INTRODUCTION

The Internet is one of the most astonishing technological breakthroughs inherited from the twentieth century; lifestyles have dramatically changed since Internet arrived with, perhaps, communication receiving the most profound effect. Aided by abundance of user friendly smart phones equipped with mobile instant messaging (MIM) applications like WhatsApp and Blackberry Messenger (BBM), old barriers to communication caused by spatiotemporal factors were shattered as the new order of real time, synchronous chat defied status quo, reconfigured communication and made all-day/ round-the-clock interaction a routine.

Mobile instant messaging applications are Internet dependent social apps that offer the same services. Regardless of provider modification, the most basic facilities MIM apps support are chats, net call, exchange of pictures, videos and voice notes between chat buddies. To enjoy these services, and other added features provided by respective apps, users in Nigeria need only subscribe or buy data bundles at specified rates from GSM service providers. This allows users stay in touch with their chat buddies via their preferred MIM app(s) even if they have no airtime for phone calls. Alternatively, in the 
absence of a data subscription, users can connect to Wi-Fi if available. While one must solicit the Personal Identification Number (PIN) and receive same from others to become chat buddies on BBM, WhatsApp simply manages ones phone contact list and instantly updates contacts already on the messenger for chatting to begin.

In Nigeria, 91.6million people are connected to the Internet (NCC, 2017). Akinola \& Okunade (2016) report that young people between the ages of 18 to 45, mostly students of tertiary institutions form the substantial majority of Internet users in Nigeria; that they access the Internet through their mobile phones and mostly later in the evening and that majority of them use the Internet more for social networking. Ericsson's April 2015 country report on Nigeria also indicate that $82 \%$ of mobile phone users access the Internet with their mobile devices daily and that $97 \%$ of mobile/ smartphone users engage in instant messaging activities.

Although there is a preponderance of mobile instant messaging applications, it appears there is a subtle cultural preference that conditions, the adoption and popularity of particular MIM applications in certain places. For example, we observe that WhatsApp and BBM are noticeably widespread MIMs in Nigeria, whereas other applications like WeChat, Viber, QQ and Kakaotalk are either not known or used sparingly by a few. Shambare et al., (2012) report that WhatsApp is extremely popular among South Africans, while there is an observed decline in the use of other services such as SMS and BBM. This study therefore focuses on WhatsApp and Black Berry Messenger (BBM) because of their per- ceived popularity among young people in Nigeria.

WhatsApp messenger is a 'cross-platform messaging app which allow users to exchange messages without having to pay for SMS' The application is compatible with iPhone, BlackBerry, Android, Nokia, and other Windows smart phones (WhatsApp.com, 2016). Introduced into the market in 2009, by the fourth quarter of 2017, WhatsApp is reported to have 1.5 billion subscribers who send over 60 billion messages per day (Coustine, 2018). As a matter of fact, as at 2016, WhatsApp was rated the world most popular mobile messenger apps worldwide (Statista, 2016). Blackberry smart phone was introduced to the market in 1999. With 100 million active users, it is ranked seventh behind QQ mobile, WeChat, Skype, Viber, and LINE respectively (Statista, 2016).

The exponential growth of WhatsApp within nine years of its introduction is by no means a great accomplishment. Shambare (2014) suggests that this rapid diffusion and widespread adoption of WhatsApp is worth exploring. Bradshaw (2011) observed that the introduction of WhatsApp signified the gradual decline in usage rates of other textbased messaging services, such as instant messaging, Blackberry messaging (BBM), and short message service (SMS). Preference and adoption of WhatsApp over other textbased messaging services is attributed to a combination of cost efficiency, simplicity, user friendly features, and the ability to run on multipleplatforms (Shambare, 2014).

At the cost and functional levels, WhatsApp proves to be more advantageous to consumers than BBM. Whereas, BBM subscribers pay about US\$ 5.5 monthly subscription fee, WhatsApp service is free. Secondly, whereas 
CONSTRUCTIO N OF EROTIC NUANCES ON WHATSAPP AND BBM BY ...

in the case of ordinary SMSs, subscribers are billed in 160-character intervals, and thus a 161-character SMS is billed as two SMSs, WhatsApp subscribers do not experience such restrictions (WhatsApp.com, 2012; Bradshaw, 2011). Bouhnik \& D eshen (2014) also identified simplicity, low cost (if any) and privacy (in comparison to other social networks like Facebook or Twitter) as features that made WhatsApp a prime choice of young learners. The Internet through mobile instant messaging apps is used for a variety of purposes. Apart from keeping in touch with loved ones, it is used for sending and receiving advertising and marketing messages (Akinola \& Okunade, 2016); it provides a sexual space midway between fantasy and action (Ross, 2005); has potential for learning enhancement (Smit, 2012) among other potentials. The features include one-on-one chat, group chat, push notifications, sending and receiving both video and audio files. There is no doubt that the introduction of Internet and various MIMs has added value to the individual and the society. Mobile instant messaging applications foster social bond between family and network of friends because it facilitates continued interaction between chat buddies regardless of time and proximity; by mediating real time interaction MIMs creates a pseudo nearness between people making them popular lifestyle necessities.

The above notwithstanding, the negative implications of these technologies has attracted numerous researches and societal concerns. Apart from health related issues, online sexual abuse and violence remain a critical concern to government and the society. A correlation has been drawn between Internet related technologies and morality with the conclusion that Internet technolo- gies significantly devalues moral standards. George and Ukpong (2013) wrote that some contemporary social problems in Nigeria like pornographic videos, indiscriminate sexual activities, and sexual lawlessness are readily available on the Internet and are by-products of technology. In a March 2015 report, Pew Research Center found that a median figure of $42 \%$ users in emerging and developing nations say the Internet is bad on morality; specifically, $50 \%$ of users in Nigeria say Internet has a negative influence on morality ( $p$ 29,30 ).

There is substantial research into how Nigerian youths use MIM apps for academic purposes, but the crux of this study is to gain an understanding of how Nigerian youths construct erotic nuances on BBM and WhatsA pp. In doing this, this study will investigate factors influencing the adoption of WhatsApp and BBM applications, the nature and patterns of erotic communication among young adults in tertiary institution in Nigeria. To achieve these objectives, data will be collected and analysed to answer the following research questions: Between WhatsApp and BBM, on which one does erotic communication occur more? What form(s) does erotic communication take on WhatsApp and BBM? What type of relationship exists between parties involved in erotic communication? Who initiates erotic conversations more, male or female?

\section{Literature Review}

Across the world, influences of social media on students have fascinated scholars and studies abound on how social media impacts academic performance. On a positivenegative dichotomy, most studies found that social media injure students' focus, concentration and, ultimately, academic performance. Students were found to use messag- 
ing apps for seven main motives that are affection, inclusion, sociability, entertainment, relaxation, escape and fashion (Leung, 2001) cited in Singh, 2014). Similarly, Griffiths (2000) says Internet can be (and has been) used for a number of diverse activities surrounding sexually motivated behaviour: Seeking out sexually-related material for educational use; buying or selling sexually-related goods for further use offline; visiting and/ or purchasing goods in online virtual sex shops; seeking out material for entertainment/ masturbatory purposes for use online; seeking out sex therapists; seeking out sexual partners for an enduring relationship; seeking out sexual partners for a transitory relationship; seeking out individuals who then become victims of sexually-related Internet crime (online sexual harassment); engaging in and maintaining online relationships via E-mail and/ or chat rooms; exploring gender and identity roles by swapping gender or creating other personas and forming online relationships; and digitally manipulating images on the Internet for entertainment and/ or masturbatory purposes (Griffiths, 2000:537-538).

Many school managers and administrators have strongly advocated for the integration of Internet as an educational tool into the school system. However, basing his argument on a survey of teachers, librarians, and computer coordinators, he warned that Internet usage by children does not improve performance; $86 \%$ of the respondents argued that information on the Internet is too disorganized and unrelated to school curriculum to help students and can even serve as a distraction (Barber, 1997). Y oung (1998) also found that $58 \%$ of students suffered from poor study habits, poor grades, or failed school due to excessive Internet use. At Alfred University, investigation was con- ducted to know why successful students with 1200 to 1300 SATs had recently been dismissed. The findings revealed that $43 \%$ of these students failed school due to extensive patterns of late night logins to the university computer system (Brady, 1996). Iorliam and O de (2014) in a study that assessed the impact of social media usage on Benue State University wrote that, 'the perils of its effects on the academic performance of the overinvolved students are disturbing... the social network overuse certainly has some negative impact that may counterbalance the potential benefits and poses grave consequences to the academic performance of its victims. Students spend quality time to comment, update, read and share posts on social networks.' (p. 275). The import of these is that Internet addiction is a critical problem.

Social media apps, especially instant messaging apps, are extremely powerful, in that they derive their appeal from contributing to the 'death of distance' (Cairncross, 2011), allowing friends to stay in touch almost always this can, understandably, lead to addiction because of the tendency to feel 'I am missing out on something' Singh (2014:367). Mojaye (2015) specifically identified addiction as one of the adverse effects of using mobile phones by Nigerian students. Dau (2015) investigated the impact of social media addiction among northern Nigeria students; from a total of 716 respondents, 397 (55.5\%) indicated they are strongly addicted, 203 $(28.4 \%)$ said they are moderately addicted while 115 (16.1\%) said they are never addicted. The same study found that Whatsapp ranked second most used social app with 600 $(83.9 \%)$ of the participants using it. In a Chennai, India study, Jisha and Jebakumar (2014) reported 96 of 100 respondents said mobile messaging is a necessity for them and that majority of them use Whatsapp to chat 
CONSTRUCTIO N OF EROTIC NUANCES ON WHATSAPP AND BBM BY ...

first, with friends followed by family. Most students multi-task, dividing their attention between socializing on social apps and other important responsibilities. The inability to digitally detoxify and consequently get absorbed in frenetic chatting is a major disadvantage of mobile instant messengers. Incessant message notifications and pings can be intrusive and attention dividing especially for students who need maximum concentration to study.

Singh, Chopra and Kaur (2014:270) in another study that examined relationship between Whatsapp addiction and behavioural and psychological behaviour of youths in Jalandhar District, Punjab, India, cited Gross (2004) thus: 'sexual predators and exposure to pornographic materials have all been identified as consequences of excessive smartphone use.' The trio concluded that there is significant connection between shyness, loneliness, feeling stressed and moody behaviour and Whatsapp addiction tendencies. Ross (2005:344) says the Internet enables experimenting with sexual behaviours by 'engaging in it online and with another person without actually "doing" it". He notes that, while the actors in online erotic chatting may not perceive that they are engaging in real behaviour as there is no direct physical contact, their online interactions can be seen as an externalizing of sexual fantasy. A survey conducted by Stanford University in 2000 concerning Internet pornography usage revealed that men prefer visual erotica, such as still photos and video pornography, at the rate of 2 to 1 more than women (Pornography, 2003), and that women prefer interactive erotic communication, such as chat rooms and webcams, at the rate of 2 to 1 more than men (Pornography, 2003).
Erotic conversations on instant messengers are a fairly common occurrence. These kinds of conversations are intense and absorbing, they require participating chat buddies to channel a substantial part of their attention and creative energy to keep the conversation appealing. There is also an unspoken caveat between the participants to keep the conversation eyes-only which invariably predisposes heightened secrecy. Erotic conversation on Whatsapp and BBM can lead to the exchange of nude pictures or videos, pornographic materials, sexually charged voice notes and more. There is an abundance of adult BBM channels on which explicit erotic conversations occur, no-holds barred. Participants on such channels who strike a cord of intimacy can simply exchange PINs to enjoy a more private interaction. 'Perceived enjoyment influences intentions to use mobile chat services are stronger for women as compared to man. The effect of perceived usefulness on intention to use a technology is related to instrumental behaviour (i.e. sociability, flirting and enjoyment)' (Singh, 2014:368).

The Ericsson Country Report on Nigeria (2015) indicated that $97 \%$ of instant messaging occurs indoors as against 37\% that occurs outdoors. This gives an indication of when erotic conversations are likely to occur given its own nature which requires a measure of concentration and privacy. The objective of this study is to gain an understanding of how erotic conversations are constructed from the perspective of selected students in Nigeria. Can the same logic be extended that erotic gratification is an addictive act among Nigerian students who use Whatsapp and BBM? 


\section{Theoretical Framework}

This study is situated within the framework of Uses and Gratification Theory (UGT). The UGT holds that people have specific needs or requirements which they actively seek to satisfy by selectively and deliberately choosing media that suit their preferences. The theory focuses on how individuals use media and why (Vivian, 2006). Analysing the idea that people use media for specific needs connected to personal characteristics and social environment, Weiyan (2015) wrote that 'problems and solutions resulted in different motives for gratification behaviour which is produced by using the media. In turn, the gratification (or nongratification), produced by using media or other behaviours, also has an influence on the individual or society, therefore starting the process again and again.'(p.72). WhatsApp and BBM are used by different categories of people to gratify needs that follow from personal preferences. The insular focus of UG T may result in conflict between individual and social norms, a situation which can lead individuals to pursue their needs overtly or covertly.

In principle the Nigerian society frowns at brazen sexual and erotic activity, in practice eroticism and suggestive sexual nuances are rife especially among youthful population. Erotic nuances carry a pleasure incentive that motivates Nigerian youths to seek media that gratifies their need; the internet and social media are readily used for this purpose because discretion, content and control are entirely up to individual users. The manner in which primordial erotic drive and pleasure is conducted on WhatsApp and BBM as means used to satisfy an end is what this study investigates.

\section{METHODOLOGY}

There are a number of published works on the usage, impact and effects of Internet and social media. Very little research has been done on how erotic nuances are constructed using WhatsApp and BBM. The intension of this study is to provide the spring board for further studies in this particular area. The main purpose of this study is to gain an understanding of how erotic nuances are constructed on WhatsApp and BBM from the perspective of users. Hence, this exploratory research merely intends to explore 'if', 'who' and 'nature' of erotic conversation among youths of tertiary education level. This study does not offer a final or conclusive solution to the problem; it rather sets the framework upon which further studies can be conducted.

The qualitative method was adopted for the study. Twenty willing participants, ten males and ten females, were randomly selected from among National Diploma (NDI) students of Mass Communication Department of Lagos State Polytechnic, Isolo Campus, Nigeria and year three and four students of Mass Communication Department of Olabisi Onabanjo University, Ago-Iwoye, Nigeria. The selected population were adequately briefed about the study; they were equally assured that their identity will not be revealed, and that their responses will be used strictly for academic research purpose. Seventeen (17) semi-structured interview questions relating to the objectives and research questions were posed to the selected study population. The study was carried out over a period of two weeks, with each session lasting between forty five minutes and one hour. The session with each participant began with explanation of the research and its purpose including participant's rights. The researcher allowed participants to speak 
CONSTRUCTION OF EROTIC NUANCES ON WHATSAPP AND BBM BY ...

freely, explain and describe their ideas bet- scribed, grouped into themes and quantitater. The responses were thereafter tran- tively analysed.

\section{FIN DINGS AND DISCUSSION}

The findings of this study covers six main divisions presented as follows:

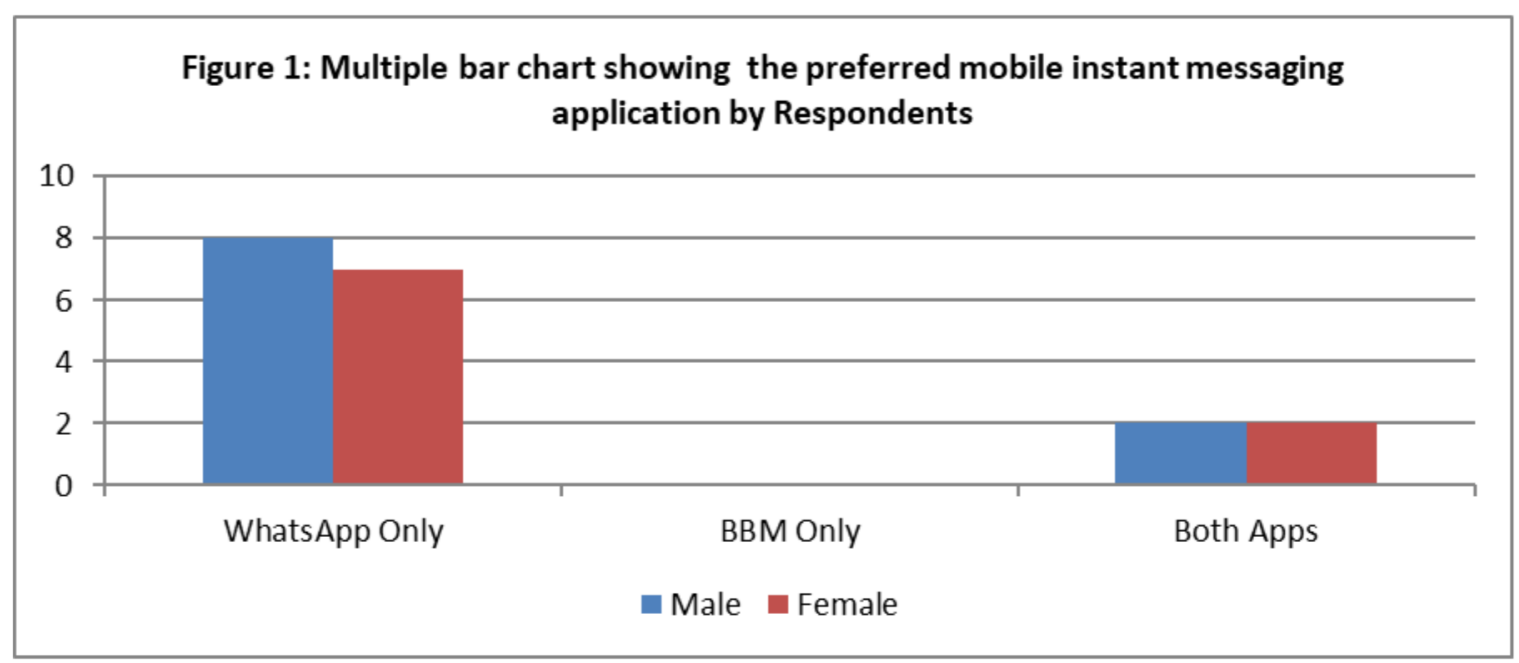

Respondents' preference was for WhatsApp instant messenger. Table 1 shows that fifteen respondents, regardless of gender, use WhatsApp. Five respondents use both WhatsApp and BBM. Three of the respondents who use both apps said they use BBM sparingly while the other two multitask between both messenger apps. All the respondents however expressed preference for WhatsApp over BBM for the following reasons:

- WhatsApp is easier to use,

- WhatsApp has a friendlier, simpler, and has a more appealing interface display,

- WhatsApp consumes less data
- It costs significantly less amount to purchase data for WhatsApp unlike high rates of subscribing for BBM data packs,

- Messages deliver faster on WhatsApp

- WhatsApp functions on low-end operating system phones unlike BBM that requires high versions

- WhatsApp is an easy, ready to use app that simply manages phone contact list and updates contacts already using (or new on as the case may be) the messenger for interaction to begin unlike BBM that requires one to solicit and receive PIN for any conversation to occur. 


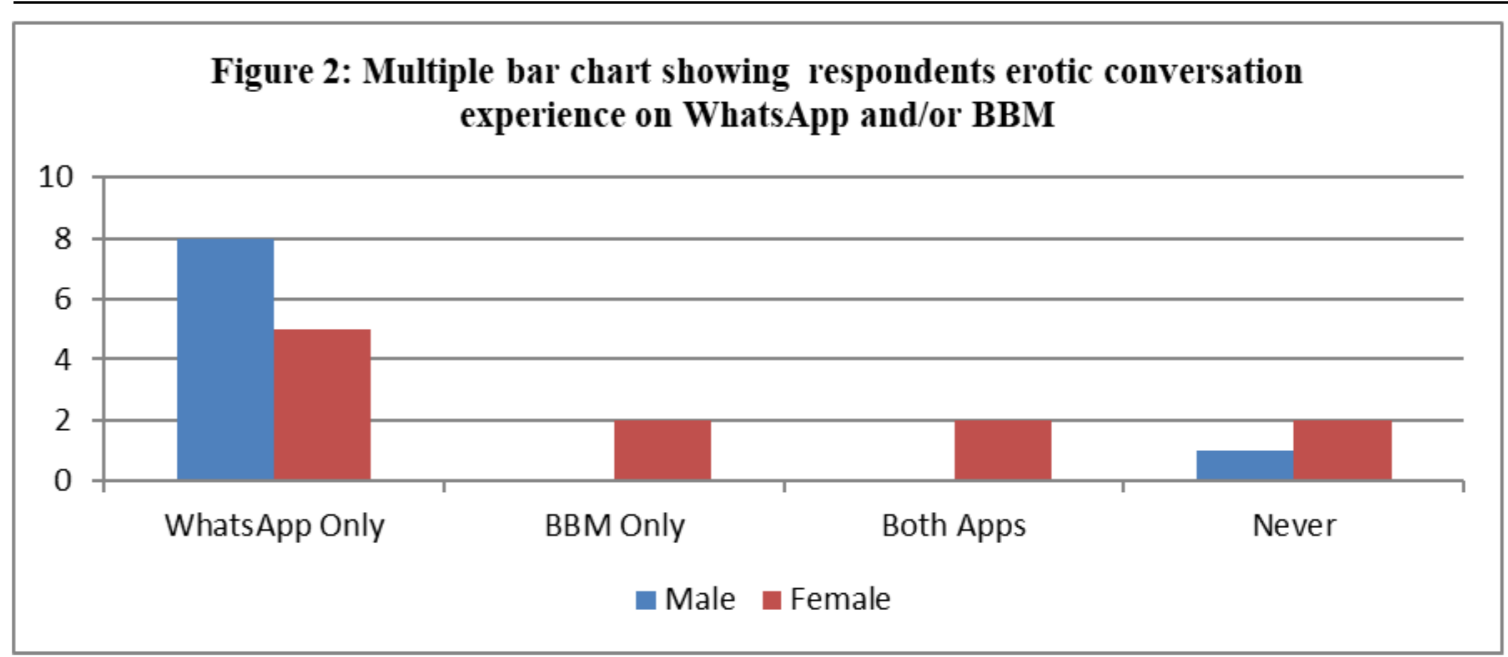

Figure 2 above indicates that the incidence of erotic conversations was higher on WhatsApp (note: the definition of erotic experience is any nuance understood by participants' to be laced with sexual undertones either initiated or received by participants). O ne of the female respondents who had erotic experiences on BBM said all her experiences were from foreigners including lesbians. The only two female who had erotic experience on both apps said, on
WhatsApp strangers who got their contact numbers from group chats initiated erotic conversations with them while their singular experience on BBM was from a lesbian channel disguised as an innocuous forum. In all, seventeen of the respondents have experienced erotic conversation; thirteen on WhatsApp only, two on BBM only, two on both WhatsApp and BBM and three claimed never to have experienced erotic conversation on any of the MIM apps.

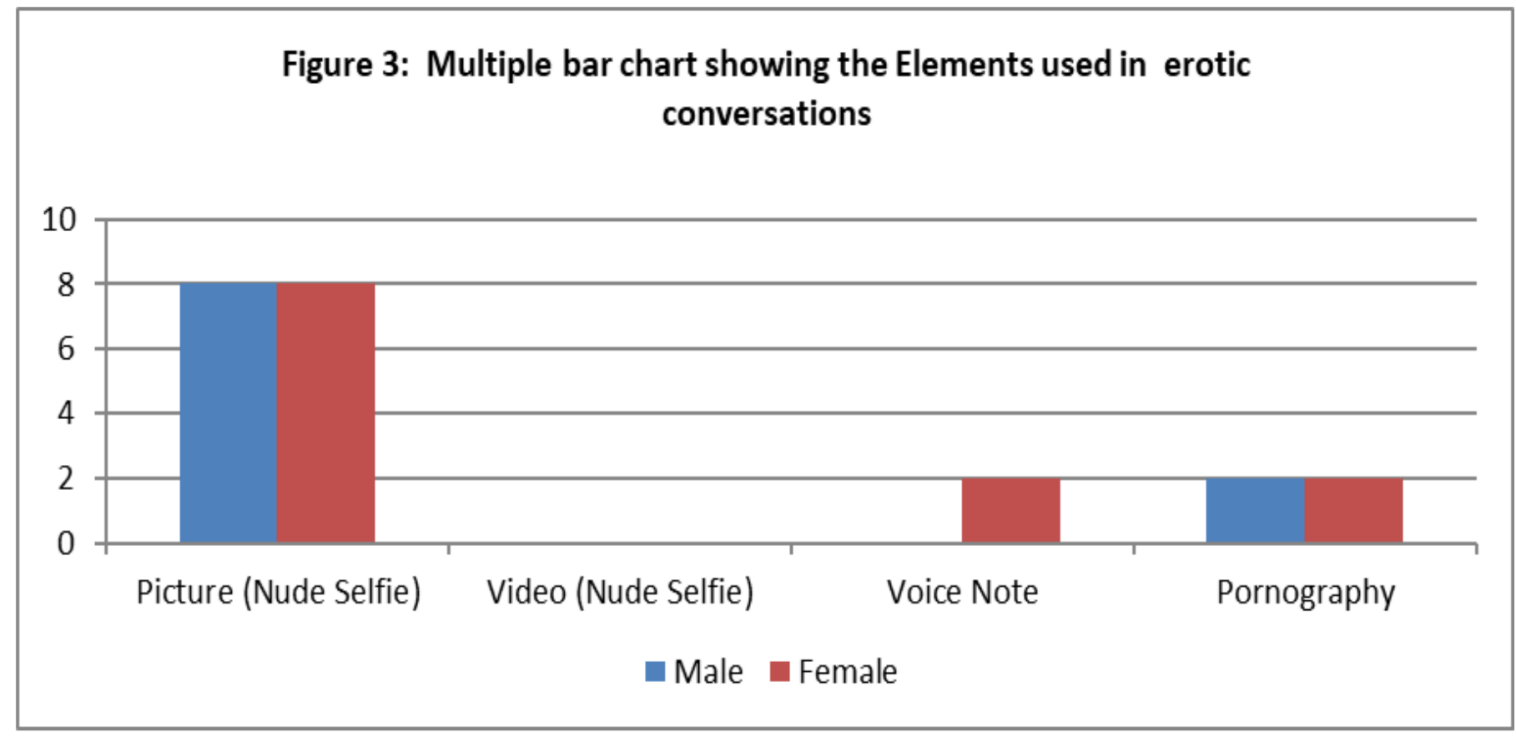

J. Hum. Soc. Sci. Crtv. Arts 2018, 13: 1- 13 
CONSTRUCTIO N OF EROTIC NUANCES ON WHATSAPP AND BBM BY ...

Respondents' indicated that more of nude stimulating. All the respondents claimed nev'selfie' pictures and occasional pornography were used to enhance erotic conversations, the nude pictures explicitly showed genitals and other body parts considered sexually er to have sent any explicit material of themselves in any of the erotic conversations they had engaged in, rather, they only received.

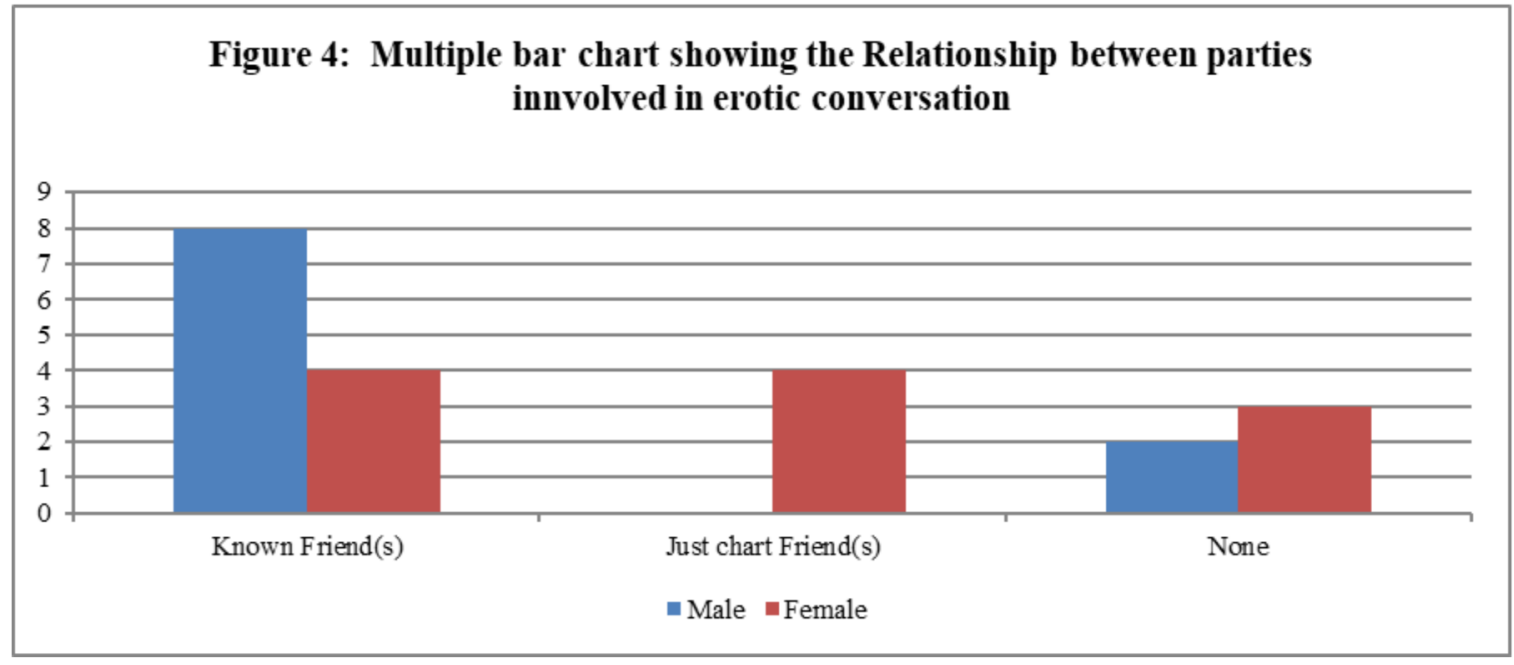

Physical familiarity featured prominently as a factor that predisposes erotic chat between chat buddies as twelve of the respondents said people they had erotic conversation with were known friends. The four female who were involved in erotic chat with 'Just chat' friends claim these persons must have got their contacts from chat groups they belong. From the responses, it was obvious that romantic relationship need not exist for erotic conversation to begin; mere friendship alone is enough to trigger erotic chat between chat buddies although romantic feelings and an existing love affair energizes the occurrence of explicit chat.

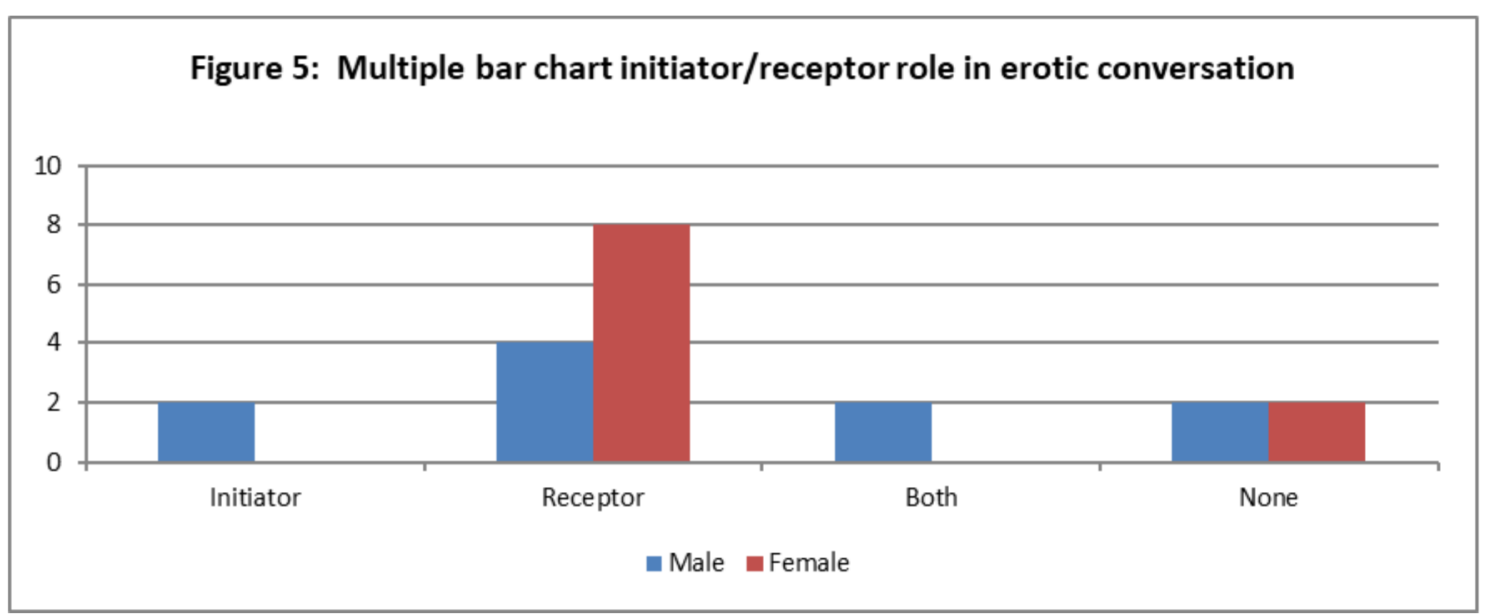

J. Hum. Soc. Sci. Crtv. Arts 2018, 13: 1- 13 
All the female respondents indicated that they always received erotic conversation intention from males. This may not be unconnected to the cultural belief that men should make sexual advances. However, four male respondents confessed to have initiated erotic conversation with their female chat buddies, while six male respondents also said female chat buddies initiated erotic chat with them. On the balance, in the initiator/ receptor role, each gender place in the construction of erotic chats on WhatsApp and BBM is close to call.

\section{Table Showing N uances Suggestive of E rotic Chat Intention}

The following are answers participants gave as actions indicative of a chat buddy's intention to have erotic conversation. The answers are collated from each participant's response and grouped according to gender.

\begin{tabular}{|c|c|c|}
\hline $\mathbf{N}$ & From Female to Male & From Male to Female \\
\hline 1 & $\begin{array}{l}\text { Any statement open to several in- } \\
\text { terpretations e.g I'm hungry. }\end{array}$ & When male asks how last sexual activity felt. \\
\hline 2 & Request to know if male has lover. & When male asks if a female has a lover. \\
\hline 3 & $\begin{array}{l}\text { Request to know if male has previ- } \\
\text { ously had sex. }\end{array}$ & When male asks if female is a virgin. \\
\hline 4 & $\begin{array}{l}\text { Outright request for sex or erotic } \\
\text { chat. }\end{array}$ & $\begin{array}{l}\text { When male asks if a female is alone and feel- } \\
\text { ing cold. }\end{array}$ \\
\hline 5 & $\begin{array}{l}\text { When female refers to her body } \\
\text { part(s) reporting a kind of sensa- } \\
\text { tion. }\end{array}$ & $\begin{array}{l}\text { When male requests to know a female's age } \\
\text { described as a guise to gauge exposure. }\end{array}$ \\
\hline 6 & $\begin{array}{l}\text { Confession of romantic feeling for } \\
\text { male. }\end{array}$ & When male says he wants female partner. \\
\hline 7 & $\begin{array}{l}\text { When female asks last time a male } \\
\text { was with the lover. }\end{array}$ & $\begin{array}{l}\text { When male says he wants to take care of fe- } \\
\text { male. }\end{array}$ \\
\hline 8 & $\begin{array}{l}\text { When female asks whether a male } \\
\text { has ever been alone with lover } \\
\text { without having sex. }\end{array}$ & $\begin{array}{l}\text { When male says he wants to be close to fe- } \\
\text { male. }\end{array}$ \\
\hline 9 & $\begin{array}{l}\text { When female displays scantily clad } \\
\text { picture of herself. }\end{array}$ & $\begin{array}{l}\text { When male use display pictures with sexually } \\
\text { charged inscriptions like I'm hungry, I'm } \\
\text { alone etc }\end{array}$ \\
\hline 10 & - & $\begin{array}{l}\text { When raw, outright comments are made } \\
\text { about body in an erotic manner. }\end{array}$ \\
\hline
\end{tabular}

All the participants said they use Whatsapp particularly to keep in touch with friends, have fun, gossip or 'gist' and kill boredom or, at times, get information they require. The probability of erotic conversations happening seems to increase with boredom be- cause there is a tendency to seek an interesting and lively relief usually from chat buddies. Although most of the participants indicated that they do not particularly like erotic conversations, the experience could be indulged in if it is with a lover, for pleasure or 
CONSTRUCTIO N OF EROTIC NUANCES ON WHATSAPP AND BBM BY ...

curiosity. Unlike physical, unmediated interactions same gender friendship is prevalent, majority of the participants categorically said they prefer and enjoy chatting with opposite gender because it is more interesting and open.

\section{CONCLUSION}

WhatsApp instant messenger is the choice messenger app of participants and most erotic conversations occurs on it. Physical familiarity between chat buddies tends to aid the occurrence of erotic chat which explains why most participants reported erotic experience majorly on WhatsApp, which is perceived as an application for continuing existing bonds. On the other hand, BBM is not so favoured by participants for chatting for technical, operational and financial constraints - the same reasons participants prefer WhatsApp.

The danger of over-exposure to internet pornography and erotic communication, particularly amongst young people is that, it has the potential of encouraging multiple partners and drug abuse (See, BraunCourville \& Rojas, 2009). The increasing rate of rape cases and other sexual related misbehaviours on our campuses may not be unconnected to the ease with which young people exchange erotic experiences and materials courtesy WhatsApp instant messenger. The fundamental right to freedom of expression notwithstanding, WhatsApp administrators will do the society a lot of good by regulating contents, particularly sexually explicit material. Parents, opinion moulders and influencers should equally consider engaging young people on the dangers of erotic communication on social media.

\section{REFERENCES}

Akinola, 0. 0., Okunade, D. 0. 2016. Evaluating the use of internet as a medium for marketing and advertising messages in Nigeria. African Jarmal of Markeing Manage met, Vol. 8(2), 12-19.

Ashiyan, Z., Salehi, H. 2016. Impact of WhatsApp on learning and retention of collocation knowledge among Iranian EFL learners. Adwances in Langrage and Literary Studies, Vol. 7 (5), 112-127.

Barber, K. 1997. Readings in African popular alture Indiana, USA: Indiana University Press.

Bouhnik, D., \& Deshen, M. 2014. WhatsApp goes to school: Mobile instant messaging between teachers and students. Jaumal of Infomation Techndogy Eduration Re serch 13, 217-231.

Braun-Courville, D. K., Rojas, M. 2009. Exposure to sexually explicit web sites and adolescent sexual attitudes and behaviors. Jamal of Addescent Helth, 45, 156-162.

Constine, J. 2018. WhatsApp hits 1.5billion monthly users \$19B? Not so bad. https:/ / techcrunch.com Retrieved, July 12, 2018.

Dau, B. 2015. Social computing: A study assessing the impacts of social network addiction among the students in Northern Nigeria. Intemational Jaumal of Humanities and Managenent Saieneses 3(1), 37-40.

Enicsson Consumer Insight Summary Report. 2015. Internet goes mobile. Country report,

Nigeria.http:// down1.Ia4.u2.ucweb:80// download.php? $\underline{\mathrm{i}}=\mathrm{a}$ e662c1ab28c10b. Retrieved, June 27, 2016. 
George, I.N., Ukpong, D.E. 2013. Contemporary social problems in Nigeria and its impact on national development: implications for guidance and counselling services. Jaumal of Edurational and Social Reserrch $3(2)$.

Griffiths, M. 2000. Sex on the Internet Issues, Concerns and Implications . In Feilitzen, C.V. and Ulla, C. (Eds) Children in the New Meela Landscape Games, Pomography, Peceptions Goteborg , Sweden: The UNESCO International Clearinghouse on Children and Violence on the Screen.

Griffiths, M. 2000. Excessive Internet Use: Implications for Sexual Behavior. Cyberpsychology \& Behavior Vol. 3, (4), 537-552.

Ionliam, A., \& O de, E. 2014. The impact of social network usage on university students academic performance: A case study of Benue state of University, Makurdi, Nigeria. Intemational Joumal of Computer Saiences andEngineeing 6(7). 275-279.

Jisha, K., Jebakumar. 2014.Whatsappp: A trend setter in mobile communication among Chennai youth. Jaumal of Humanities and Social Saience, 19(9), 01-06.

Mojaye, E. M. 2015. Mobile phones usage and its impact on teaching and learning. Gldbal Jaumal ofArts Humanities and Social Säences 3(1), 29-38.

Nigenian Communications Commission (NCC). 2018. Nigeria's internet user rise to 91.6million. The Communicator Magazine https:www.ncc.gov.ng. Retrieved, July 11, 2018.

Pew Research Centre. 2015. Internet seen as positive influence on education but negative on morality in emerging and developing nations. http:/ / www.pewglobal.org/ files/ 2015/ 03/ Pew-Research-CenterTechnology-Report-FINA L-March-1920151.pdf. Retrieved 25, June 2016.

Pew Research Centre. 2015. Mobile messaging and social media 2015 www.pewinternet .org. / 2015/ 08/ 19/ mobile -messaging-and-social-media-2015 . Retrieved 25 June, 2016.

Shambare, R. 2014. The Adoption of WhatsApp: Breaking the Vicious Cycle of Technological Poverty in South Africa. Jarrnal of Econamics and Behavioral Studies Vol. 6, No. 7, pp. 542-550, July 2014

Singh, J. 2014. Mobile messaging through android phones: An empirical study to unveil the reasons behind the most preferred mobile messaging applications used by college going students. Intemational Joumal of Multidis apdinaryand Cument Research Vol.2, 367-372.

Singh, N., Chopra, N., Kaur, J. 2014. A study to analyze the relationship between psychological behavioural factors on Whatsapp addiction among youth in Jalandar District in Punjab D isrict. European Jaumal of Business Management, 6(37), 269-273.

Statista Inc. 2016. Most popular messaging apps. http:/ / www.statista. Com/ statistics / 258749/most-popular-globalmobile-messenger-apps/ Retrieved June 12, 2016.

Vivian, J. 2006. The media of mass commuica tion(7th ed.). Boston: Pearson Education.

Weiyan, L. 2015. A historical overview of uses and gratifications theory. Cross-Cultural Communication. 11(9). 71-78. D oi: 
$10.3968 / 7415$.

WhatsApp Inc. 2016. One billion. https:/ / blog.Whatsapp.com.616/ one-billion. $\mathrm{Re}$ trieved June 20, 2016.

Wikipedia. 2016. List of virtual communities with more than one million active users. https:/ / en. m.wikipedia.org/wiki/ list_of_virtual_communities_with_more than_ 100-_million_active_users. Retrieved June $21,2016$.
Yeboah, J., Ewur, G.D. 2014. The impact of Whatsapp messenger usage on students' performance in tertiary institutions in Ghana. Jaumal of Eduration and Pradice, 5(6), 157164.

Young, K. S. 2004. Internet Addiction: A New Clinical Phenomenon and Its Consequences. American Behavioal Säentist, Vol. 48 (4), 402-415.

(Manuscipt reeived 18thJuly, 2018; accepted 23rdJanuary, 2019). 